\title{
Analysis of droplet displacement during transport of polydisperse emulsion as drug carriers in microchannels
}

\author{
Mariola Błaszczyk ${ }^{1}\left[\right.$ ] Jerzy Sęk $k^{1} \cdot$ tukasz Przybysz $^{1,2}$
}

Received: 31 August 2021 / Accepted: 23 January 2022 / Published online: 10 February 2022

(c) The Author(s) 2022

\begin{abstract}
Drug transport in human body is often intensified by various carriers. The simplest and highly effective are emulsions. In these liquids, one phase is dispersed in other in the form of droplets, in which active substance is often dissolved. In existing application of such liquids as carriers, monodispersity of such systems has been a very important parameter, because when all droplets have same size, it is relatively easy to predict drug release time. However, monodisperse emulsion production on an industrial scale is expensive and technologically quite difficult. Therefore, it would be more reasonable to use polydisperse emulsions. However, mechanism of drug release from such carriers is more complicated and difficult to conduct. When emulsion droplets of different sizes pass through microchannels, i.e., blood vessels, individual droplets' transport velocity is different and interdependent. The ability to predict rate at which individual droplets travel through microchannels will enable control of drug release depending on emulsion parameters. This work presents a detailed analysis of polydisperse emulsion transport through a single microchannel. Dependence of individual droplets velocity on their diameter and position relative to flow axis and influence of these parameters on droplet transport trajectories were studied. These studies were conducted for five liquid flow rates and three emulsion concentrations. As a result of this work, some generalization approach was proposed to estimate droplet transport velocity depending on their position in channel based on reference to single-phase flow. This work may find application in pharmaceutical industry for design of cheaper drug manufacturing technologies.
\end{abstract}

Mariola Błaszczyk

mariola.blaszczyk@p.lodz.pl

1 Department of Chemical Engineering, Faculty of Process and Environmental Engineering, Lodz University of Technology, Wólczańska St. 213, 90-924 Łódź, Poland

2 Department of Refrigeration Technology and Techniques in Lodz, Prof. Waclaw Dabrowski Institute of Agriculture and Food Biotechnology, State Research Institute, Al. Marszałka J. Piłsudskiego 84, 92-202 Łódź, Poland 


\section{Graphical abstract}

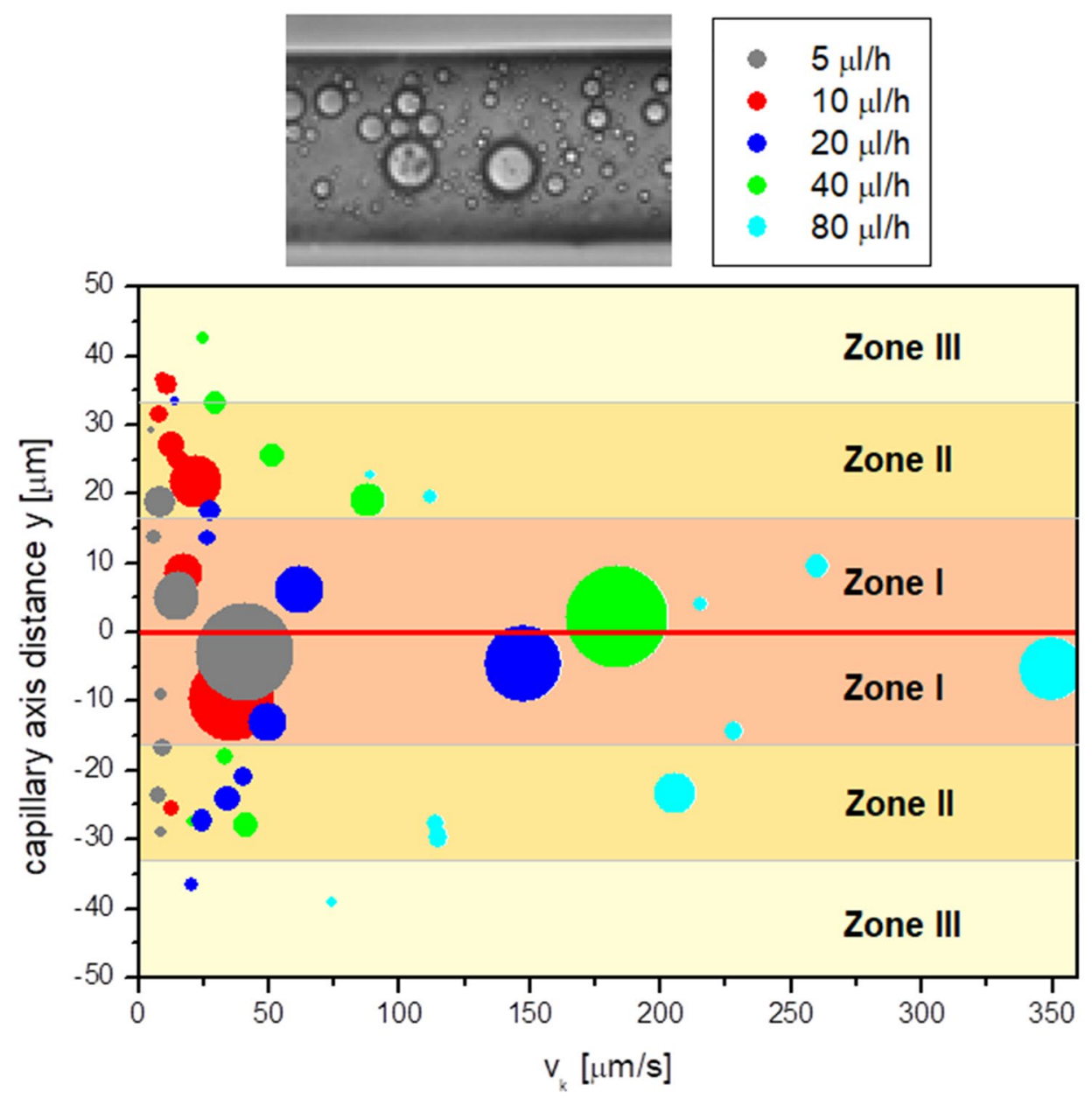

Keywords Drug delivery $\cdot$ Emulsion carriers $\cdot$ Skin permeability $\cdot$ Emulsion transport

\section{Introduction}

The transport of dispersion systems, like emulsions or suspensions, especially in small, micro- or nano-structures, plays a fundamental role in many fields of science and industry, such as, inter alia, medicine, the pharmaceutical industry, cosmetic, or the oil extracting industry (Lopes et al. 2020; Rahman et al. 2020; Shui et al. 2007; Shah et al. 2021; Scheffer et al. 2021). Knowledge of the transport mechanisms of such liquids in microstructures is important when analyzing the movement of various types of particles or droplets through the circulatory system, including blood cells or cholesterol particles or even drugs introduced into the regime (Ohkawa et al. 2020; Troendle et al. 2018). It becomes important to estimate how fast these media will flow, how the speed will depend on their size or shape, where they will stop, and how they will affect the movement of other components. Thanks to this information, it will be possible to predict the occurrence of various embolic conditions in the circulatory system, which may contribute to faster diagnosis of diseases and response through the use of appropriate medical treatments.

Knowledge of the transport mechanisms of dispersion systems is also of great importance in the design of modern drugs, especially those that use carriers for transport in the human body (Gordillo-Galeano and Mora-Huertas 2018; Ran et al. 2017; Di et al. 2020). The active substance contained in such a carrier has a chance to precisely reach a specific place in the body at a certain time and be released there and manifest its healing properties. Carriers of such active substances can be various types of microparticles, microdroplets, microcapsules, or microgels (Sattari et al. 2020). They constitute various types of structures, but their role is to trap a given substance during transport and release it in a 
specific place (Ding and Li 2017). Among these, especially important are single or multiple emulsions, where the active ingredients are placed in the droplets of the dispersed phase (Zhao 2013). The advantage of such liquids is both: the relative ease of creating these structures and different affinity for the surface of the channel through which they move, due to the presence of the oil and water phases (Xu et al. 2021). For this reason, they are gaining more and more interest not only in their application through the circulatory system, but also in transport through the skin structures (CzajkowskaKośnik et al. 2019; Hiranphinyophat et al. 2021). Such structures consist of layers of different lipophilicity and correspond well with the oil and water phases of the emulsions (Mirtaleb et al. 2021). Of course, the transport of emulsion carriers through the skin layers requires transition of flow mechanisms to a smaller nano scale. Research in this regard may contribute to the development of new techniques for non-injection of drugs into the human body. This may have advantages in avoiding possible cross contamination caused by the use of over 150 years old needle injection technique. This is of great importance, mainly in less-developed countries, especially at a time when, in the face of a pandemic, the entire population is waiting for vaccinations. Therefore, the search for new, safer ways to introduce drugs becomes of key importance, and any research on the transport mechanisms of dispersion systems in small structures may contribute to the development of these alternative techniques.

The use of emulsions as drug carriers is well known and has been the subject of many studies in the literature (Ran et al. 2017; Di et al. 2020; Zhao 2013; Xu et al. 2021; Dong et al. 2019; Patil and Deshpande 2018). However, in order for such a carrier to fulfill its function, it was necessary to create an emulsion with the narrowest possible distribution of droplet sizes, i.e., close to monodisperse. This is especially important as the size of the droplets directly affects the rate of drug release. The more similar size of the drops, the greater certainty that the release will be uniform (Di et al. 2020; Zhao 2013). However, it is very difficult and expensive to create monodisperse emulsions. Most often, various types of drop generators are used for this purpose, (Sattari et al. 2020; Zhao 2013; Sartipzadeh et al. 2020; Nabavi et al. 2017a, b; Koppula et al. 2016; Zhang et al. 2016). However, the effectiveness of existing techniques, despite intensive research, is still quite low and does not meet the production needs. Therefore, one should consider whether it would not be justified to use polydisperse systems as carriers, which can be produced in large quantities at relatively low costs. But with such emulsions, the release time will be faster for small droplets and longer for larger droplets. This will result in an overall increase in the rate of the release time, as evidenced by the works (Shin et al. 2009; Xu et al. 2009a, b; Yang et al. 2007; Huang et al. 2009). However, if we had an appropriate model, supported by a series of quantitative experimental studies, to predict the velocity and trajectory of individual emulsion droplets depending on their diameter, we could determine where the droplets will travel at a given time. This, in turn, will allow planning the controlled release of drugs.

The analysis of the transport of various substances, including multi-phase ones, through the structures of the human body, including the skin, is considered in the literature on the subject in terms of the diffusion process and is often described using the Fick's law or its modification (Couto et al. 2014; Nitsche et al. 2019; Siepmann and Siepmann 2012; Ibrahim 2018). However, such an approach refers only to changes in the concentration of the substance under consideration. It does not include the phenomena occurring inside the structure during the flow, and even less the interactions between the phases. Therefore, such a conventional recognition of this issue is an approach based on the so-called "black box" model where only the input and output parameters are analyzed without going into the essence of the process. Seeing that, there is a need for a different way of considering the transport of multi-phase systems, including emulsions, in terms of the analysis of the phenomena occurring inside the structure during the movement of individual phases, as this may provide valuable new information.

Transport of emulsion systems in capillary or porous structures has been studied and modeled many times, especially for the purpose of searching for methods of intensifying the extraction of crude oil from oil-bearing rocks (Lee and Babadagli 2020). Various models were developed here, describing the process on a macroscopic scale, where the sensitivity of phenomena occurring during transport were captured, which made it possible to estimate such parameters as the relative reduction of permeability or the degree of blockage of the deposit (Blaszczyk et al. 2016a, b, 2017, 2020). There is opportunity to find some interesting papers describing the formation of water-in-oil disperse flows investigated in a microfluidic device (Belkadi et al. 2015, 2016). These works studied the formation of emulsion systems in cross-flow regimes at high fluid flow rates. The results of these works were of particular importance for enhanced oil recovery.

However, by penetrating the structure and analyzing the transport of individual emulsion droplets in individual pores or capillaries, valuable information can be obtained that will find its application, among others, in medicine or the pharmaceutical and cosmetic industry. In the literature on the subject, there are several works (Shui et al. 2007; Perazzo et al. 2018; Liu et al. 2018; Cunha et al. 2018; Harvie et al. 2008) relating to the movement of individual droplets through a capillary. They provide valuable information on the flow resistance of these droplets, their deformation during movement or decay. However, 
there are no studies on the flow of different sized droplet clusters in such systems. It is not known how such droplets flow, what their velocities are, how they interact with each other, and how the flow conditions or their own properties affect the hydrodynamics of their transport.

Many works have been focused on the study of emulsions in microchannels. Researchers (Ji et. al. 2021a) characterized droplet size and size distribution in crossslot microsystems employing head-on impingement of oil and water jets for emulsifying and mainly focused on the effect of the cross-junction layout on the emulsion quality. The flow patterns in cross-slot microsystems employing head-on impingement of oil and water jets for emulsifying were studied (Ji et al. 2020). Droplet size measurement at different flow conditions was carried out to analyze benefits or detriments of the presence of a swirl flow and its role for the drop breakage in microsystems (Ji et. al. 2021b) during emulsifying at high throughput.

The subject of this work is to provide detailed information on the movement of polydisperse emulsion droplets in the narrow microchannels. Both the drops paths and their velocity were analyzed depending on their location along the flow path at various flow rates. The influence of the concentration of the inner phase of the emulsion on the droplet displacement was also taken into account. The hydrodynamics of individual phases and their mutual interaction were also analyzed. This led to the development of a generalization that would allow the velocity of individual droplets to be predicted for given flow conditions. This make a valuable contribution to the progress of drug delivery methods using polydisperse emulsion carriers and guide future research.

\section{Test stand and research methodology}

The research on the transport of emulsion systems in microchannels was carried out using the test stand, the photo of which is presented in Fig. 1.

The test stand consisted of a Harvard PHD 22/2000 syringe pump (1), an LEVENHUK 740T microscope (2) with M1000 PLUS digital camera, chips with hollow microcapillaries (3), lab scale (4), and a PC (5) for data acquisition. Chips used during the research (produced by Microfluidic ChipShop) were made of PMMA [poly(methyl methacrylate)]. The straight channel through which the flow took place had an equivalent diameter of $100 \mu \mathrm{m}$ and a length of $18 \mathrm{~mm}$. Measurements were made at the half of the channel depth. The study of emulsion transport consisted in forcing the emulsion with known parameters into the channel at a given flow rate using a syringe pump. The liquid was pumped through until reaching the steady state after $30 \mathrm{~min}$, when flow recording started with a digital camera. Then, the obtained films were analyzed. Emulsions of three different volumetric concentrations $(2.5 \%, 5 \%$, and $10 \%)$ at five different flow rates $(5,10,20,40$, and $80 \mu \mathrm{l} / \mathrm{h}$ what corresponds to $1.39 \cdot 10^{-3}, 2.78 \cdot 10^{-3}, 5.56 \cdot 10^{-3}, 1.11 \cdot 10^{-2}$, and $2.22 \cdot 10^{-2} \mu \mathrm{l} / \mathrm{s}$ ) were tested. During the analysis, the trajectory of individual droplets and their velocity over time were monitored. Additionally, the diameter of each traced droplet was measured. This was performed on the basis of microscopic image analysis for each image on which a given droplet was observed. Then, the arithmetic mean of the diameters measured in each image was calculated for a given droplet. This was done to minimize possible errors in microscopic measurements.

The emulsions used during the tests were an oil-in-water system, where distilled water was the continuous phase, and the dispersed phase was vegetable oil with a viscosity of

Fig. 1 Photo of the test stand

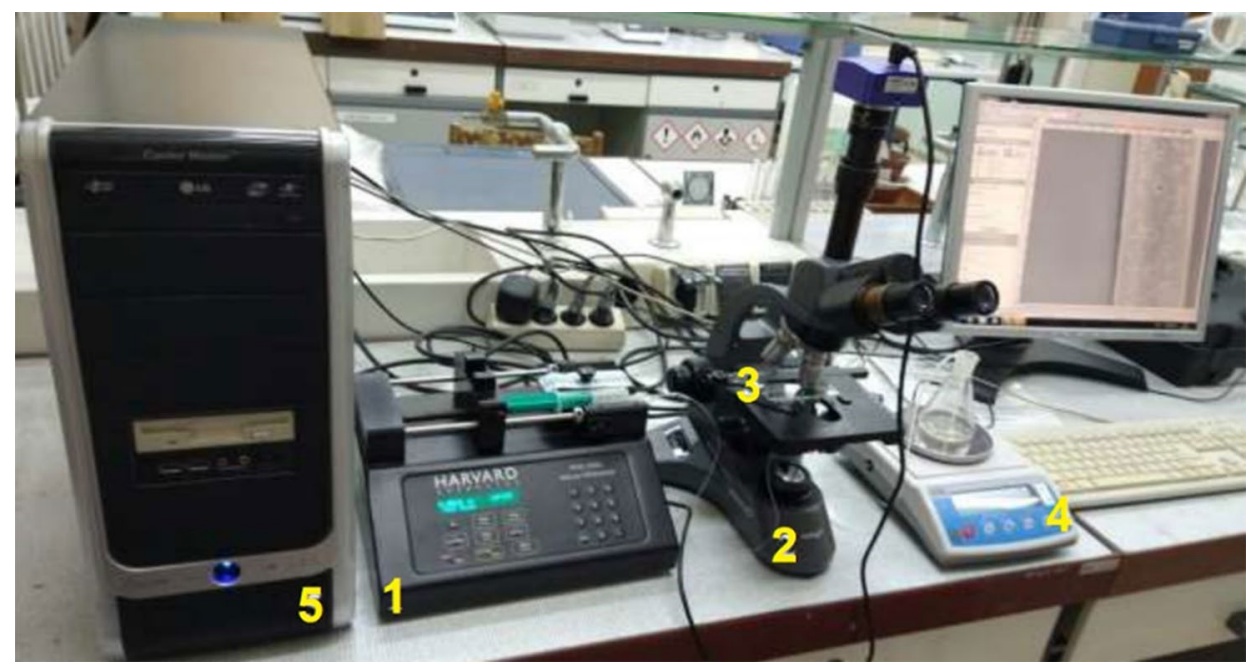


$60 \mathrm{mPa} \cdot \mathrm{s}$ and a density of $892 \mathrm{~kg} / \mathrm{m}^{3}$. The emulsifier used was a non-ionic surfactant with the trade name ROKACET 07 (PCC Rokita SA). The 10\% emulsions were prepared by mixing the appropriate volumes of oil and water with $2 \%$ vol fraction of emulsifier. Emulsification was carried out for $300 \mathrm{~s}$ using a high-speed homogenizer providing a rotation speed of 20,000 rpm.

To avoid changes in the distributions of the oil droplets diameter, emulsions with concentrations of $5 \%$ and $2.5 \%$ were made by diluting the base $10 \%$ emulsion with distilled water. The produced emulsions were then analyzed in terms of their properties and stability. The measurements of the investigated liquids viscosity were carried out using a shear rheometers Bohlin CVO-120 (Malvern Instruments, UK). The stability was measured by use optical analyzer TurbiscanTM LAB (Formulation Inc., France). All emulsions prepared behave as Newtonian liquids and the viscosity of the 10,5 , and $2.5 \%$ emulsions was $2.67 \pm 0.5,1.94 \pm 0.5$, and $1.35 \pm 0.5 \mathrm{mPa} \cdot \mathrm{s}$, respectively. Optical tests of the formed emulsions with the use of TurbiscanTM LAB for $180 \mathrm{~min}$ showed no changes in the emulsion structure, which means their stability during the study of the flow process through the microcapillaries.

\section{Analysis of the results}

\subsection{Tracking the movement of individual droplets through the capillary over time}

As presented in the research methodology, emulsions with a specific concentration and a known initial droplet distribution were passed through a capillary with a width of $100 \mu \mathrm{m}$ at a given flow rate generated by the pump. Then, after $30 \mathrm{~min}$, i.e., from reaching the full steady-state flow and video recording was started. The resulting films were divided into individual frames and analyzed with LevenhukLite and SigmaScanPro5 microscopic images analysis programs to study the movement of emulsion droplets of different diameters. Thanks to this, it was possible to determine the changes in the movement of individual droplets in each subsequent photo, which in turn (knowing the speed of film recording) made it possible to refer to the flow time. This allowed for the determination of the speed of individual droplets as well as the precise reading of the path that the analyzed drop travels through the capillary. In addition, it was possible to determine diameter of the drop.

Emulsions of three concentrations that flowed at five different flow rates, respectively, were analyzed in this way. To present the obtained results, exemplary data for the flow of an emulsion with a concentration of $5 \%$ at a given flow rate $\mathrm{Q}_{\mathrm{v}}$ equal to $10 \mu \mathrm{l} / \mathrm{h}$ were selected. The Reynolds number values were in the range of $\operatorname{Re}=0.014-0.222$, which means that the flow was laminar and even creeping. In Fig. 2, the sequence of ten selected photos is presented, in which each subsequent one shows a position of droplets at time shift of $0.588 \mathrm{~s}$.

Already on the basis of microscopic photos alone, it can be observed how the individual oil drops of the emulsion move in the capillary. First, the paths (trajectory) of ten randomly selected drops were presented, which were marked with the symbols $d_{1}$ to $d_{10}$ along with the decreasing diameter. These paths are presented in the form of distance from the axis as a function of time, which is presented in Fig. 3.
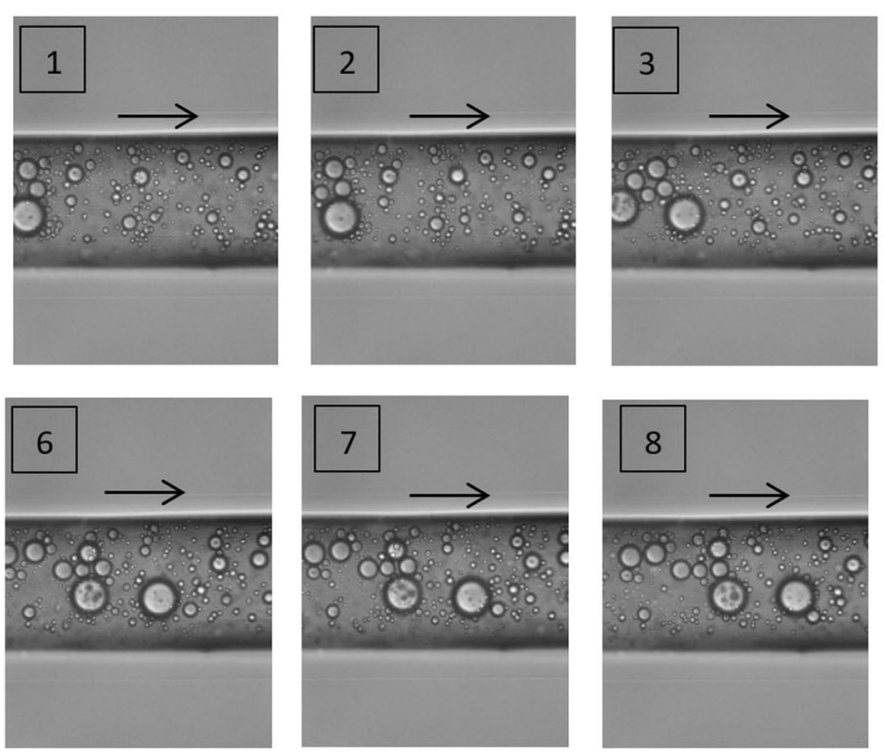
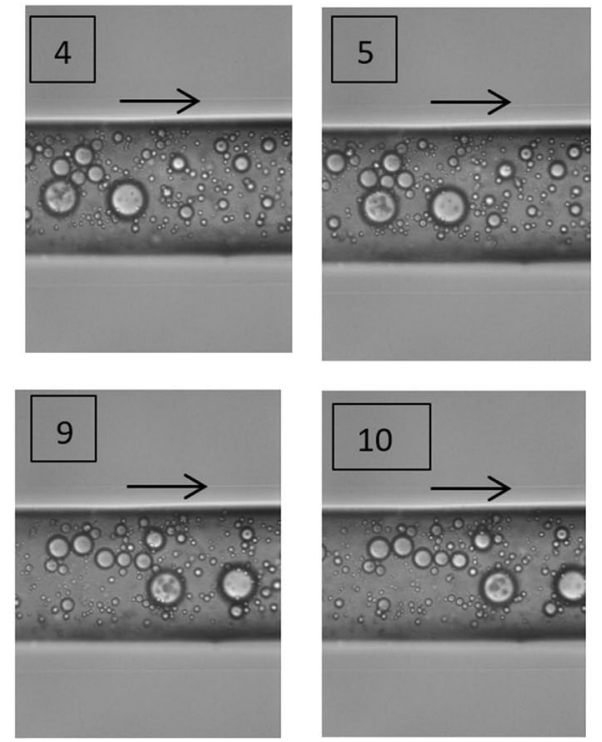

Fig. 2 A sequence of microscopic photos of the movement of a 5\% emulsion in a capillary at a flow rate of $10 \mu 1 / \mathrm{h}, \mathrm{Re}=0.028$ 
Fig. 3 Changes in the trajectory of droplets with different diameters over time for a $5 \%$ emulsion at the flow rate $Q_{\mathrm{v}}=10 \mu \mathrm{l} / \mathrm{h}$

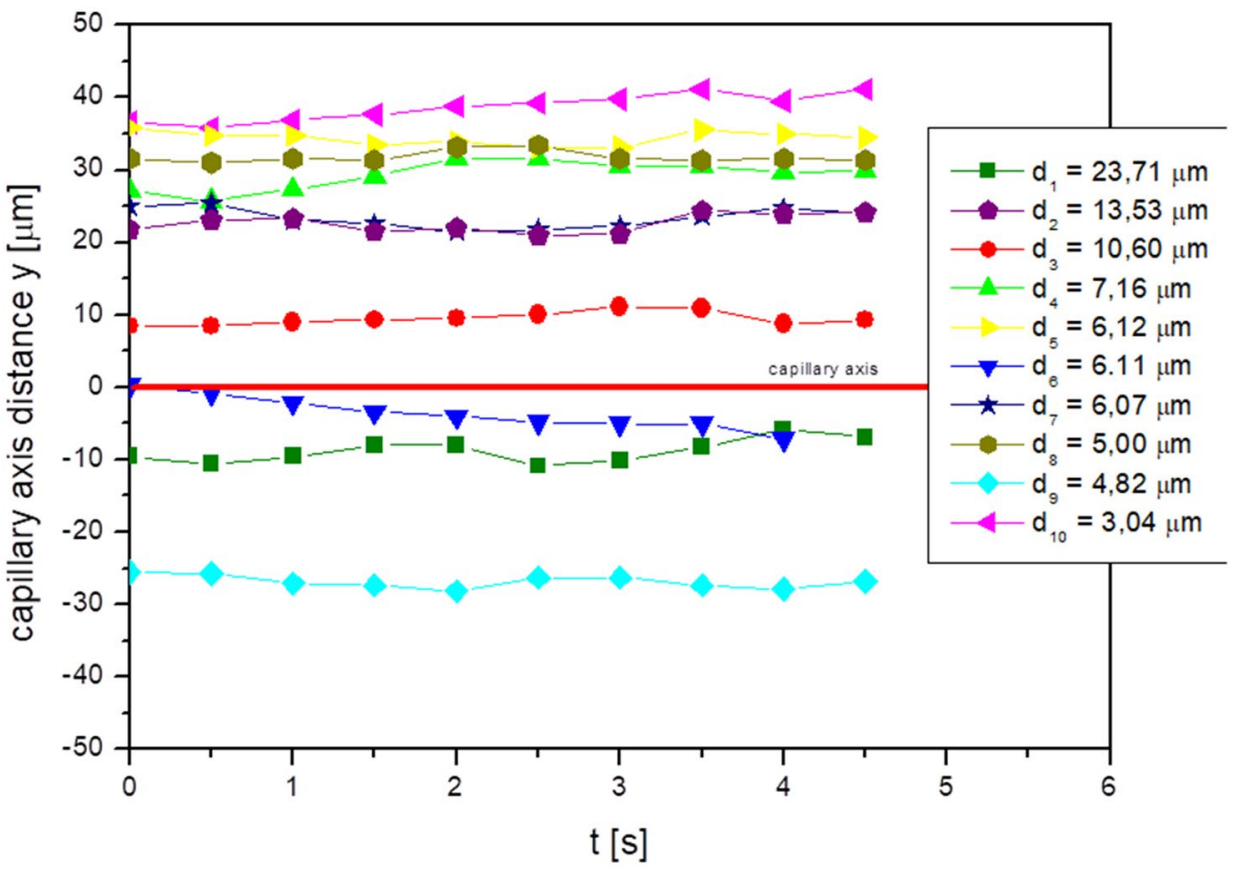

The axis of the channel is represented by $y=0$, and its walls are $\pm 50 \mu \mathrm{m}$, respectively.

On the basis of the above graph, it can be seen what a position the individual drops took in relation to the capillary axis at the beginning of the observation and how they changed this position over time. These tracks are not straight lines, they are repeatedly curved, and in some cases, they intersect with each other. This means that the droplets change position in relation to each other as they flow. They bypass also each other, circle or stop or push to the sides. This means that the path of one drop is dependent on the presence of other droplets as there is constant interaction between them. On the basis of these observations, it can be concluded that the changing trajectory of the droplets causes significant changes in their linear velocities. To determine how this linear velocity changed during the flow through the capillary for the analyzed droplets, a graph of the dependence of velocity $v_{\mathrm{k}}$ on time $t$ was prepared, which is presented in Fig. 4.

As a result of the analysis of the dependence of the droplet velocity in time, it can be noticed that the linear velocity has undergone some changes over time, which may result from local changes in the trajectory (paths) of the drops relative to each other. However, it is important how the speed of the droplets depends on the diameter of the droplets and their position in the capillary. The drops marked as $d_{1}$ and $d_{6}$ were the fastest. The higher velocity of the droplets closer to the capillary axis results, of course, from the parabolic velocity profile characteristic of laminar flows in the conduits. However, in the case of these tests, the diameter of the droplets had an important influence on the speed of the oil droplets travel. It has been observed that large droplets flow faster than small droplets if they are located at a similar distance from the axis of the conduit. An example for this observation can be drops $d_{1}$ and $d_{3}$. Both drops were at a similar distance from the axis (Fig. 3); however, the droplet $\mathrm{d}_{1}$ had a much larger diameter than the $d_{3}$. Consequently, the droplet $d_{1}$ velocity was almost three times greater than that of $d_{3}$ (Fig. 4).

A similar comparison can be made for the drops $d_{2}$ and $d_{7}$. Here, too, a similar distance from the axis can be observed, but the droplet $d_{7}$ is smaller, so its linear velocity is also smaller. Similar conclusions were drawn on the basis of all the tests carried out (for different concentrations of the emulsion at different flow rates). This means that the flow velocity of the oil droplets of the emulsion in the capillary is influenced not only by the velocity profile but also by the diameter of individual drops.

To better illustrate the relationship between velocity, position in the capillary, and the diameter of the oil droplets, the mean velocity was calculated by calculating the arithmetic mean of local velocities and the obtained values were plotted on the graph of the dependence of the initial droplet position in relation to the axis on the velocity of the analyzed drops, as shown in Fig. 5.

The results presented in Fig. 5 confirm the conclusions presented earlier. Overall, the mean velocity of the oil droplets was greater for the droplets closer to the capillary axis. However, the droplet diameter also had an impact on the average speed. On the basis of the comparison of the velocity of the $d_{2}$ and $d_{3}$ drops, it can be observed that the mean velocity of the $d_{3}$ drops was lower than for the $\mathrm{d}_{2}$ 
Fig. 4 Graph of the drop speed versus time for oil droplets of different diameters for a $5 \%$ emulsion at the flow rate $Q_{\mathrm{v}}=10 \mu \mathrm{l} / \mathrm{h}$

Fig. 5 Dependence of the initial position of the droplets on the mean velocity for a $5 \%$ emulsion at the flow rate $Q_{\mathrm{v}}=10 \mu \mathrm{l} / \mathrm{h}$
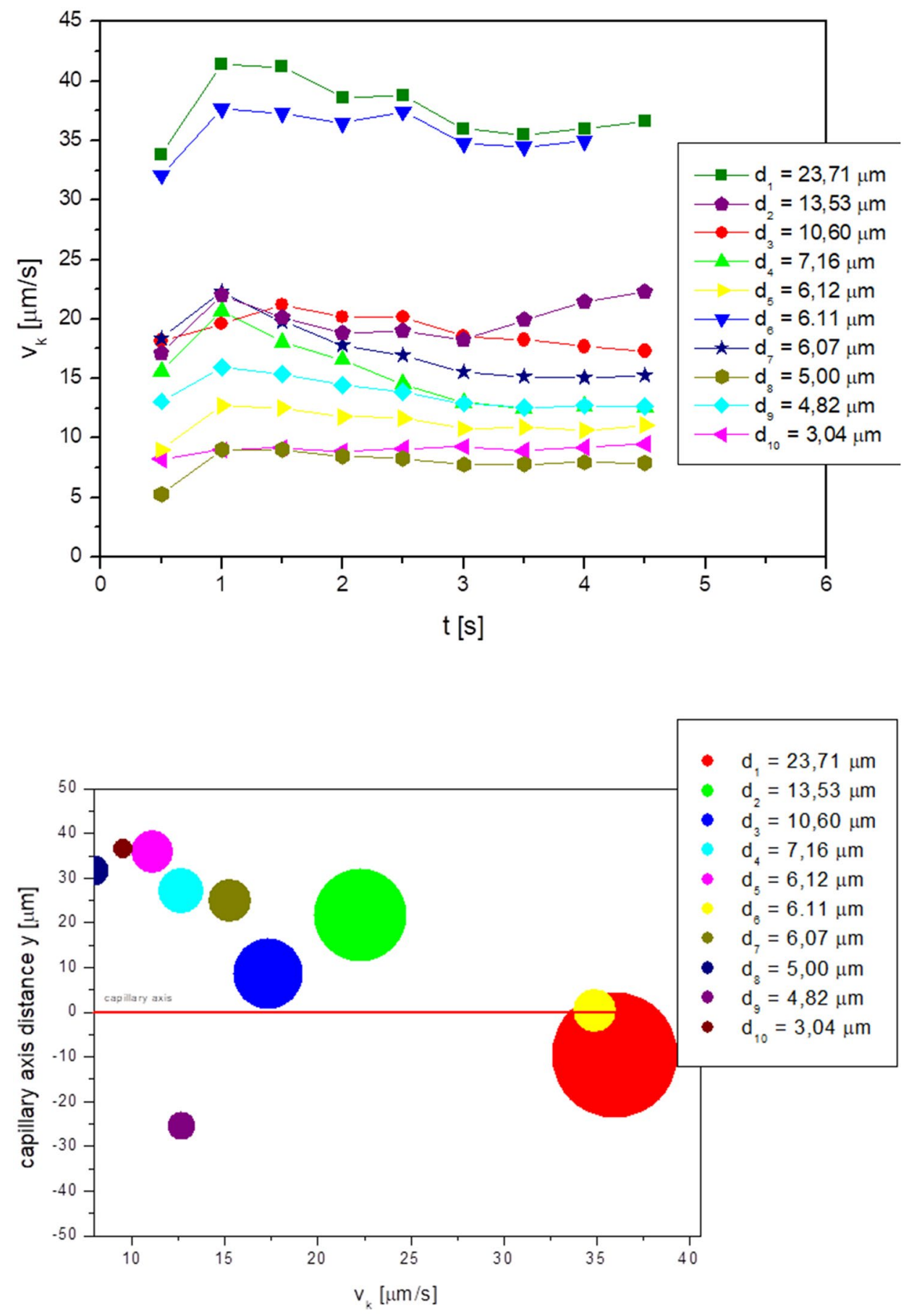

drops, although it is closer to the axis than $\mathrm{d}_{2}$, but it has a smaller diameter.

The analysis of the dependence of the size of the droplets, their position and velocity was also carried out for the flows at other given fluid flow rates. To illustrate the results of these tests, ten random droplets were selected for a given flow and the dependence of its initial position in relation to velocity was presented for five different flow rates, which is presented in Fig. 6. So that the individual drops do not overlap on the chart, they are shown at a reduced dimension 1:2 in relation to the $\mathrm{Y}$ axis scale.

The results of the experimental work carried out on tracking the velocity and trajectory of individual droplets depending on their diameter led to the conclusion that to model the transport process of polydisperse emulsions in capillary structures, both the velocity profile distribution and the size of individual droplets should be taken into 
Fig. 6 Dependence of the initial position of the droplets on the mean velocity for a $5 \%$ emulsion at the different flow rate (scale 1:2)

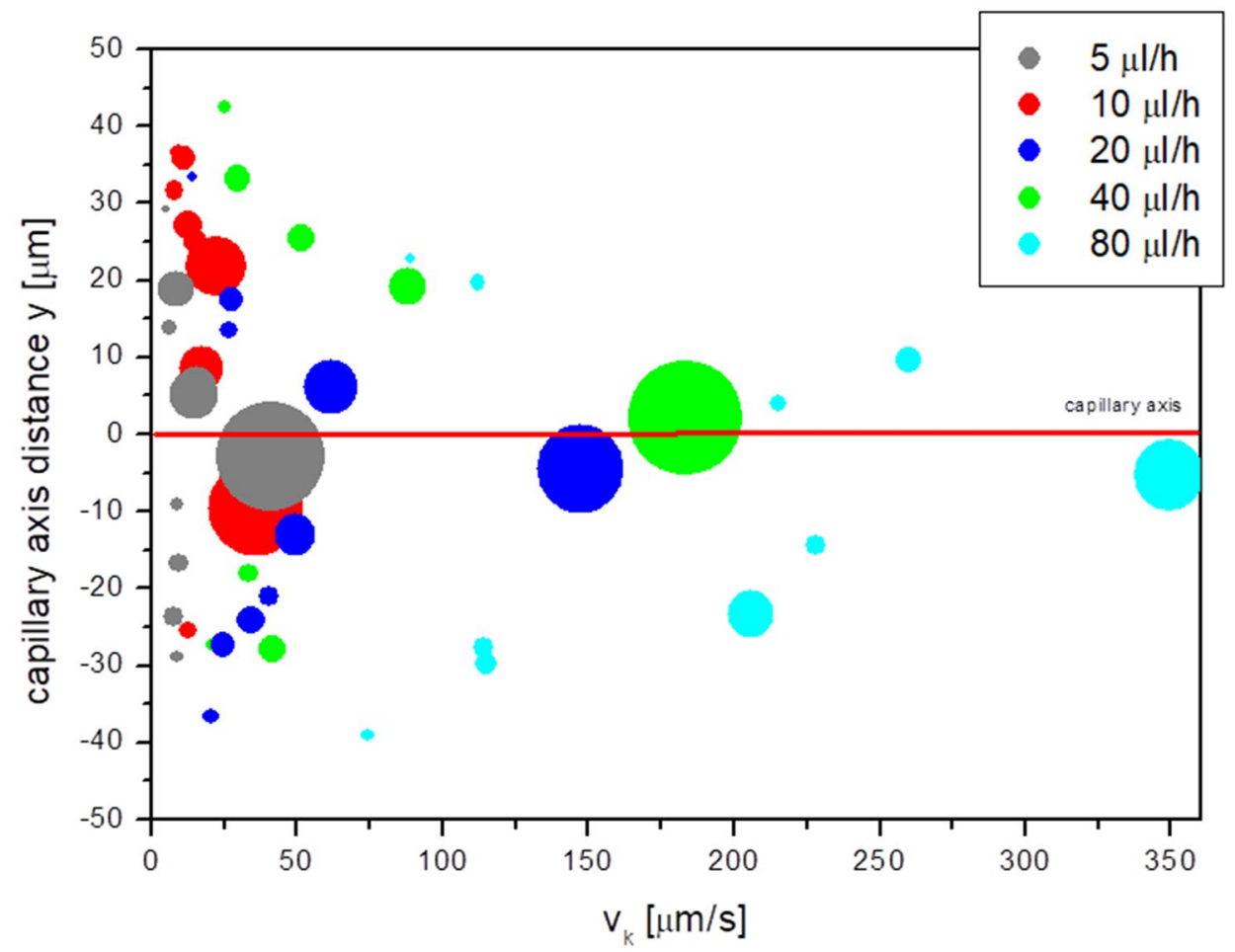

account. These conclusions became the basis for considerations in the following sections of the work.

\subsection{Analysis of the impact of the flow rate on the transport of emulsions in the capillary}

Capillary emulsion transport studies were conducted at five different pump generated flow rates. The values of these flow rates were chosen, such that each successive one was twice the value of the previous one. Thanks to this, it was possible to change the flow parameters of the oil droplets themselves depending on the set $Q_{\mathrm{v}}$. The tests were carried out at these five intensities for three emulsion concentrations: $2.5 \%, 5 \%$, and $10 \%$. Based on the flow recordings obtained, it was possible to quantify the speed and position of individual droplets. Then, the mean velocities were calculated and a comparison was made against the set flow rates. Figure 7 shows the dependence of the mean droplet velocity in relation to their diameters for different flow rates for a $5 \%$ emulsion.

As expected, the highest droplet velocities were obtained at the highest liquid flow rates. However, the influence of the diameter on the flow velocity was not clear here. Although the speed was generally increased with the increase of the droplet size for each considered $Q_{\mathrm{v}}$, it should be remembered that, as we noted earlier, the very location of the droplets in relation to the flow axis had a large impact on the speed. Therefore, it is difficult to draw any unequivocal conclusions on the basis of such a simple analysis. Due to this, it was decided to adopt a certain concept and divide the capillary into three zones, which is presented schematically in Fig. 8a. The first zone was closest to the channel axis, the second was a transition zone, and the third one related to the location closest to the channel wall. The width of these zones was the same. The idea of dividing the capillary into zones took into account the fact that the flow velocity of the droplets differed depending on the distance from the axis. The division of the capillary into zones was to consider that the flow occurs separately for each of them.

In the first zone, only those drops will be considered which, at the beginning of the tracking process, were not more than $33.3 \%$ of the distance from the axis (i.e., $16.7 \mu \mathrm{m})$. In the second zone, only those drops which were located in the distance between 33.3 and $66.6 \%$ from the axis (i.e., from 16.7 to $33.3 \mu \mathrm{m}$ ) were considered. On the other hand, in the last zone, the drops were located at a distance of more than $66.6 \%$ from the axis to the wall (i.e., from 33.3 to $50 \mu \mathrm{m})$. Knowing these division boundaries between zones, it was possible to calculate the average droplet velocities by calculating the arithmetic mean of the diameters $d_{\mathrm{ka}}$ of all the droplets that were located in the given zone. This approach allowed for taking into account the location of the droplets in relation to the center, which, as previously presented, influenced their velocity.

To avoid possible measurement errors, the droplet diameter and corresponding velocity were analyzed for ten different films (sequences of consecutive frames) obtained under the same flow conditions. On this basis, the mean diameter and mean droplet velocity in three 
Fig. 7 Graph of the dependence of the mean velocity on the diameter of the droplets for various flow rates for the emulsion $5 \%$

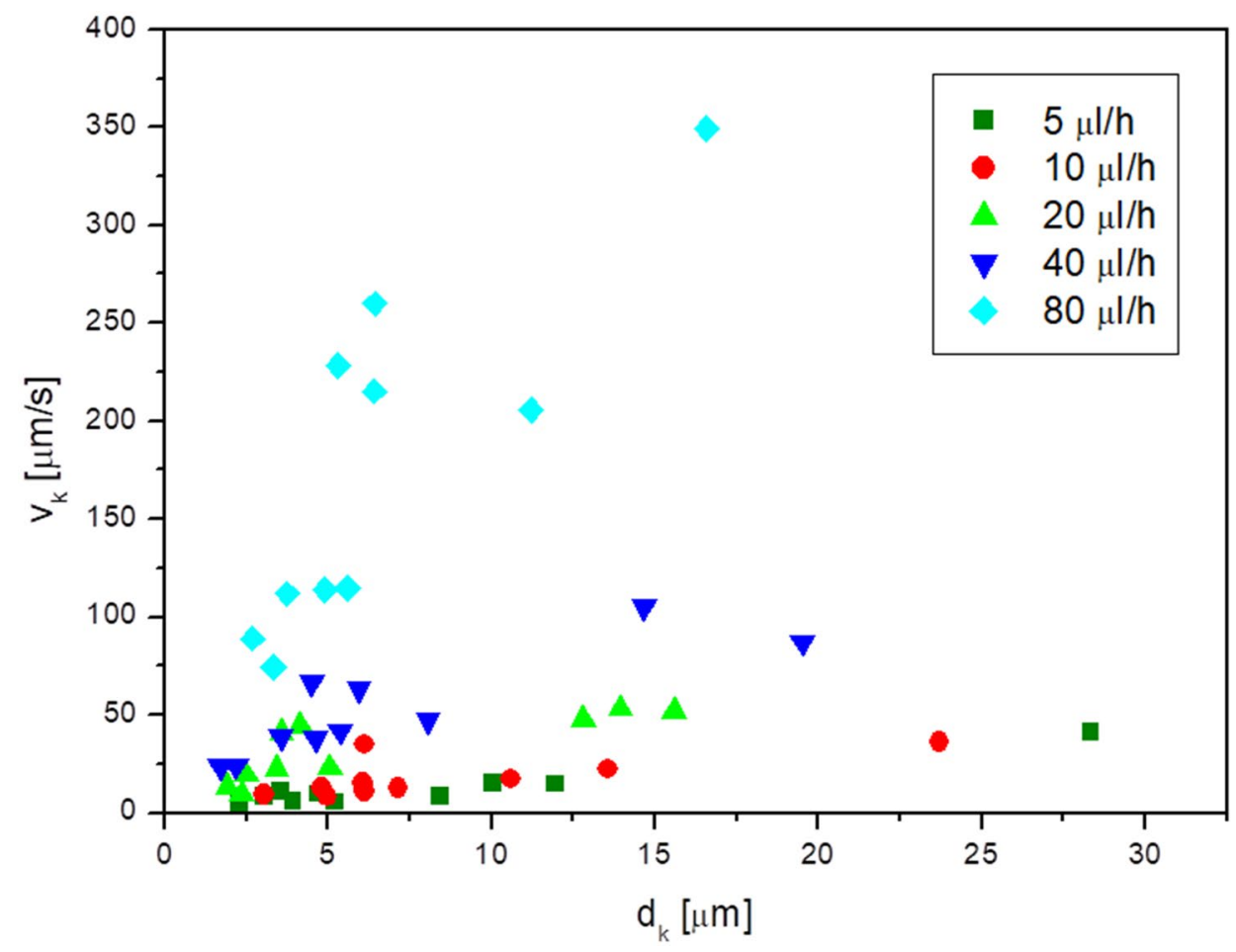

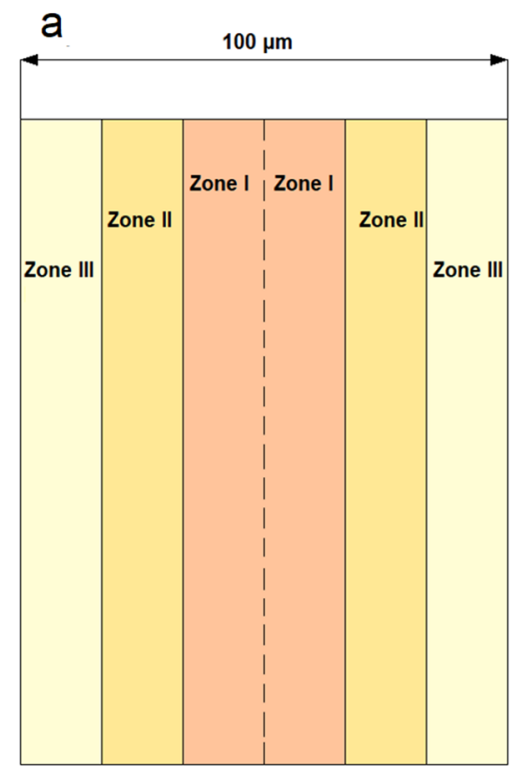

b

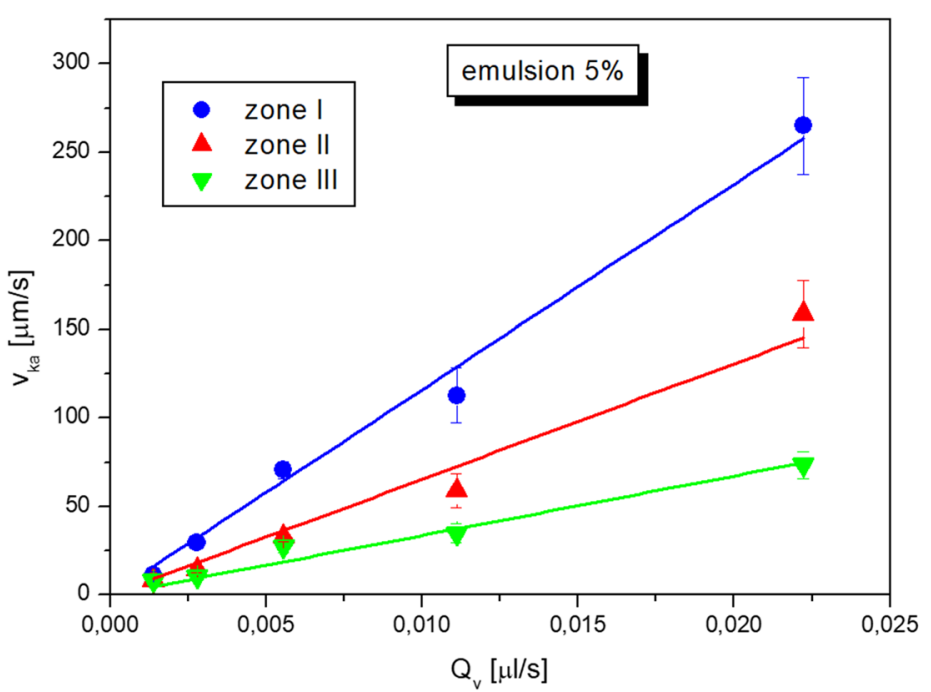

Fig. 8 a Diagram of a conceptual division of a capillary into three zones. b Graph of the dependence of the average velocity on the flow rate of the emulsion for three zones for the emulsion $5 \%$

zones (depending on the location from the duct axis) were calculated for each sample. As a result of these analyses, it was possible to determine what were the deviations of the individual measurements from the mean values. The Appendix (Table A1) presents the obtained values of mean diameters and corresponding velocity values for ten tests at a flow rate of $10 \mu \mathrm{l} / \mathrm{h}$. From these measurements, it was possible to calculate the mean diameter $d_{\mathrm{ka}}$, and the mean velocity $v_{\mathrm{ka}}$ for ten studies and the standard deviation from these mean values. Such tests were performed for the flow of the three emulsions analyzed at five different flow rates. The results of the mean diameter $d_{\mathrm{ka}}$, and mean velocity $v_{\mathrm{ka}}$ for these studies and the standard deviation from the mean values are presented in the Appendix 
(Table A2). Additionally, the Supplementary Material includes exemplary films showing the emulsion flow in the analyzed channels. The films refer to $5 \%$ emulsion flow at the following flow rates: film A $10 \mu \mathrm{l} / \mathrm{h}$, film B $20 \mu \mathrm{l} / \mathrm{h}$, and film C $40 \mu \mathrm{l} / \mathrm{h}$.

As a result of this approach, it was possible to draw a graph of the dependence of the average droplet velocity $v_{\mathrm{ka}}$ (calculated as the average arithmetic velocity of all the droplets in a given zone) on the flow rate for individual zones, which for a $5 \%$ emulsion is presented in Fig. 8b). The obtained points refer to average values; in addition, deviations from these values are also presented on the graph.

On the basis of the analysis of the results presented in Fig. 8b, certain trends can be noticed. First of all, as the flow rate $Q_{\mathrm{v}}$ increases, the droplet velocity increases; however, the greatest increase can be observed in zone I, i.e., the one closest to the axis. In zone II transition, these speeds are relatively lower, while in zone III, the lowest. The droplet transport velocities in zone III are up to three times lower than in zone I, but this relationship is not proportional. As the flow rate increases, the differences in velocity become greater. This is valuable information that must be taken into account when analyzing the movement of various dispersion carriers in small channels at relatively slow flows. The quantitative prediction of how the flow rate defines the transport of such systems in capillary structures is another challenge for the development of the field under consideration.

\subsection{Analysis of the impact of the emulsion volume fraction on the transport of oil droplets in a capillary}

The main parameter influencing the transport of emulsions in capillary structures is the share of the internal phase of the emulsion. To take this parameter into account, $10 \%, 5 \%$, and $2.5 \%$ emulsions were tested. Using the adopted concept of dividing the capillary into zones and the analysis of droplet parameters in the given zones and their averaging, it was possible to draw up individual graphs of changes in the speed of droplet movement with the change of the flow rate for the tested emulsions. Figure 9 shows this relationship for zone I, where the drops closest to the flow axis were analyzed.

As can be seen from the above graph, the volume fraction of the emulsion plays a significant role in determining the speed of the droplets' movement. A relative increase in the droplet velocity was observed for the higher concentration emulsions. The greatest changes were recorded for the emulsion with a concentration of $10 \%$, where the speed in relation to the emulsion with a concentration of $2.5 \%$ was on average almost twice as high. When comparing the $5 \%$ emulsion with the $2.5 \%$ emulsion, these differences were not that significant, especially at low $Q_{\mathrm{v}}$ values where they essentially coincided. Only at higher flow rates was it possible to observe an increase in speed by $20 \%$. As previously shown, the highest droplet transport velocities were recorded in zone I, both due to the fact that the velocity of the liquid in the flow axis will be the highest, but
Fig. 9 Graphs of the dependence of the average velocity on the flow rate of oil droplets in zone I for various volume fractions of the emulsion

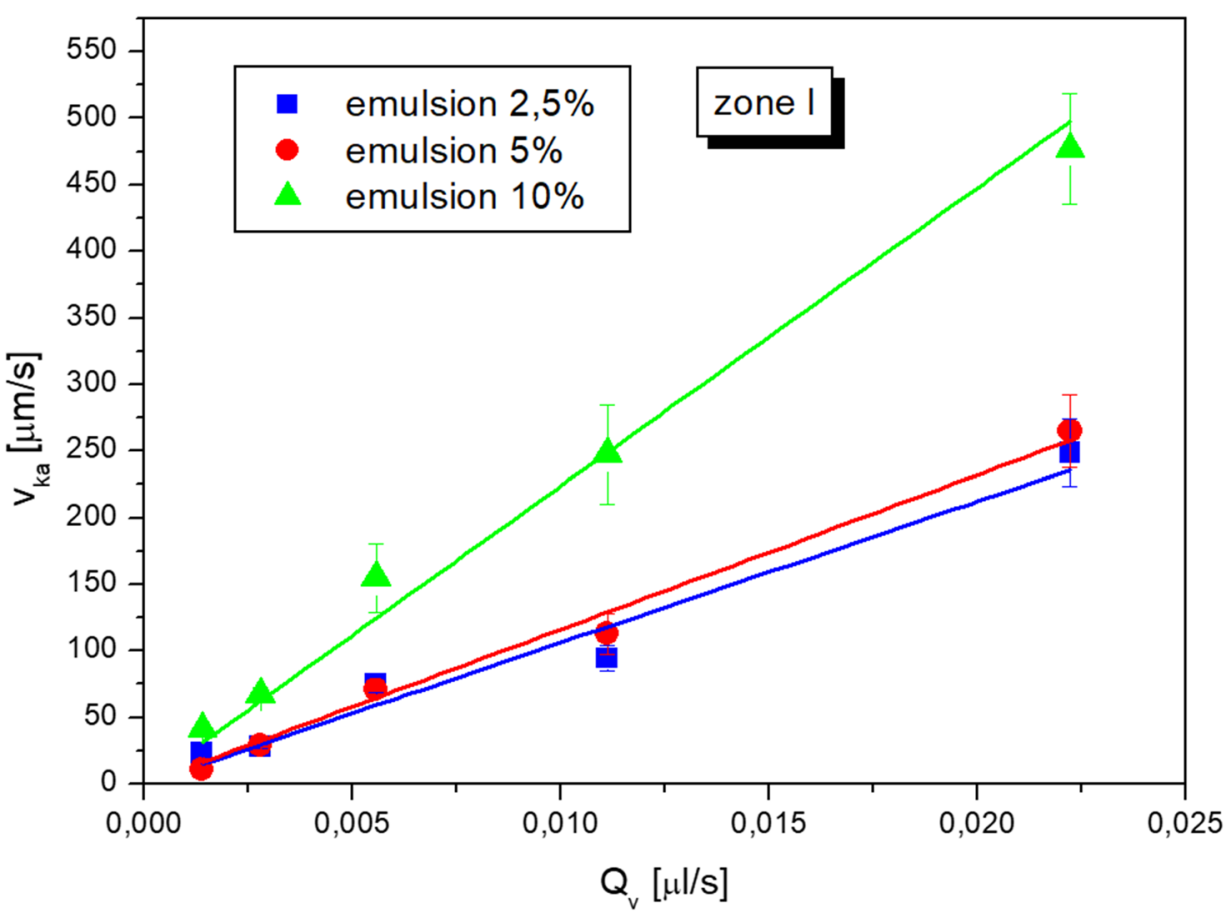


also to the fact that the largest droplets accumulated in the center of the capillary. In turn, the larger droplets were to be more difficult to avoid in the continuous phase; therefore, acting like a piston, it carried them together, giving them additionally greater speed. The diagram marked in Fig. 10a) shows adequate dependencies, but in relation to zone II (transition).

In the case of zone II, also a strong influence of the concentration of the emulsion on the speed of the oil droplets' movement can be noticed. A similar tendency is observed here, where the greater the volume fraction of the inner phase of the emulsion, the greater the measured speed of movement. Comparing the velocities measured for the $10 \%$ emulsion with those measured for the $2.5 \%$ emulsion, an over twofold average increase in speed can also be seen. Similarly to zone I, the differences in velocity for $2.5 \%$ and $5 \%$ emulsions were the greater the higher the $Q_{\mathrm{v}}$. In the case of zone III, the graph of velocity versus flow rate is presented in Fig. 10b; the effect of concentration on droplet transport can also be observed. However, the differences in velocities for individual emulsion concentrations at the respective $\mathrm{Q}_{\mathrm{v}}$ are greater here than in the other zones. For example, when comparing the average speeds measured for the $10 \%$ emulsion with the speeds recorded for the $2.5 \%$ emulsion, as much as three times higher values for the $10 \%$ emulsion can be seen. This means that the increase in the concentration of the emulsion also affects the speed of the droplets moving along the capillary walls. This is due to the fact that at high concentrations of the continuous phase of the emulsion has a problem with circumnavigation drops and seeks space for this. Due to the high concentration of droplets, there is little space, so the continuous phase acts as a piston instead of avoiding the droplets. The "plug" flow at high concentrations of the emulsion runs through the entire cross-section of the capillary, which causes that even those droplets that are near the walls are "replaced" and entrained.
This results in an increase in the velocity of the droplets farthest from the capillary axis.

Based on the above analyzes, it can be concluded that the overall droplet flow velocity is higher at higher concentrations, which may seem contradictory as an increase in concentration causes an increase in the viscosity of the liquid and thus an increase in flow resistance, which should result in a decrease in velocity. However, at higher concentrations, the concentration of the oil droplets in the emulsion is greater, which causes that the continuous phase has no space to freely evade the droplets; therefore, it acts on them as a piston and carries them together, giving them greater speed. Therefore, we are dealing here with two opposite phenomena, on one hand, an increase in flow resistance causing the droplets to slow down, and on the other hand, an increase in pressure on the drops by the water phase, which causes an increase in their velocity. Taking into account these opposing forces, it can be expected that there is some optimum at which the value of the droplet velocity is the greatest. In turn, this optimum depends on the concentration of the emulsion; therefore, it is possible to determine the concentration of the emulsion at which it will be characterized by the greatest mobility. Therefore, the possibility of predicting such a value becomes crucial, as it would allow the selection of emulsion parameters to the prevailing flow conditions, which would guarantee the greatest efficiency of movement of dispersion systems, which is of considerable importance in the design of modern drug carriers.

\subsection{Prediction of the speed of movement of oil droplets of emulsions in straight channels}

The results of the tests presented in the previous points indicate that the speed of oil droplets movement in the microchannel is influenced by parameters such as their diameter, concentration, and flow rate of the entire mass of the
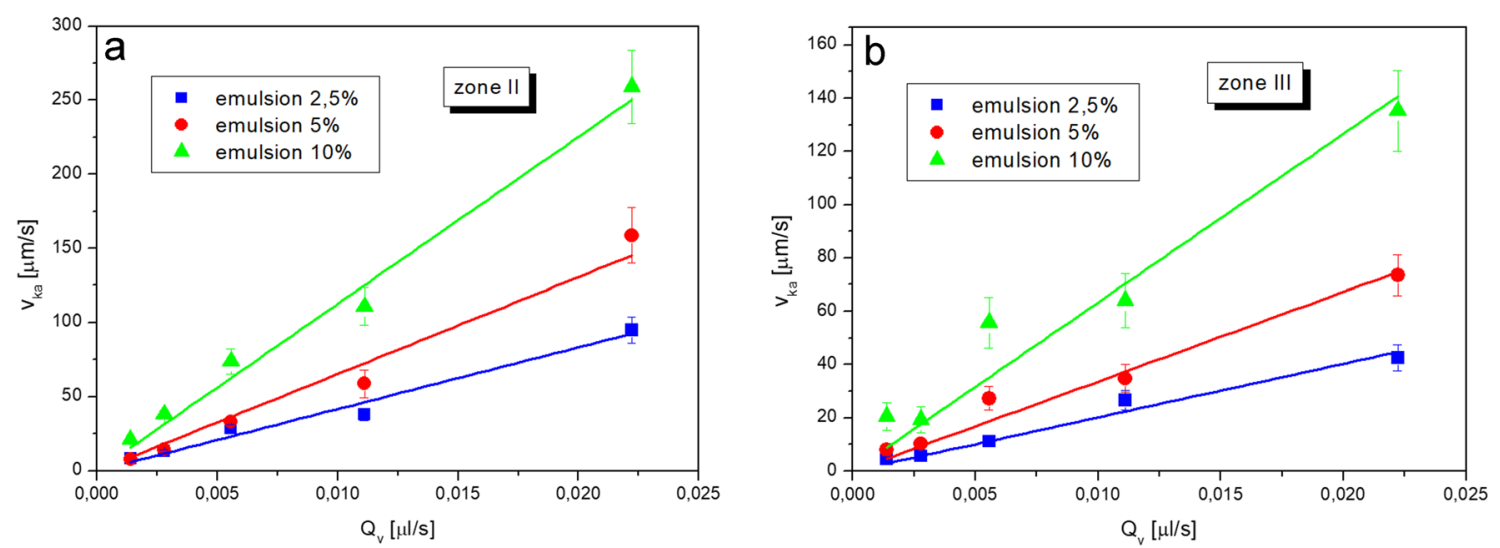

Fig. 10 Graphs of the dependence of the average velocity on the flow rate of oil drops for various volume fractions of the emulsion: a in zone II and $\mathbf{b}$ in zone III 
emulsion. Moreover, the speed of the individual droplets will also vary depending on their position in the channel relative to the axis. From a practical point of view, it is important to be able to predict the speed of the oil droplets without having to make individual measurements. For this reason, below, we have proposed some comparative approach that will allow to estimate what droplet velocities can be expected in the channel under given hydrodynamic conditions.

As presented in the graphs of the dependence of the velocity of the droplets $v_{\mathrm{k}}$ on the flow rate $Q_{\mathrm{v}}$ presented in Figs. 8, 9, 10, 11, the measurement data relating to the individual three zones were described by a straight line starting at the origin of the coordinate system (point 0,0 ), that is

$v_{\mathrm{ka}}=a_{\mathrm{k}} \cdot Q_{\mathrm{v}}$.

Here, $a_{\mathrm{k}}$ is the slope of the straight line, defined as the tangent of the slope of the line with respect to the ordinate axis. The $a_{\mathrm{k}}$ parameter values are presented in Table 1 .

The description of the transport of two-phase liquids, such as emulsions, is quite complicated and capturing all the phenomena occurring during it requires considering many parameters. For this reason, instead of analyzing what factors determine such transport, let us relate the transport of emulsions to the one-phase flow well described in the literature. Flow simulations showing the fluid velocity at continuous phase flow in the capillary, for the flow conditions considered, are illustrated in Fig. 11a). If, instead of the emulsion, a single-phase liquid (e.g., continuous phase-water) flows through a capillary with the same equivalent diameter $d_{z}$, then the calculation of the
Table 1 The value of the parameter $a_{k}$

\begin{tabular}{lrrr}
\hline & \multicolumn{1}{l}{ Zone I } & \multicolumn{1}{l}{ Zone II } & Zone III \\
\hline Emulsion 2\% & $10.6 \cdot 10^{3}$ & $4.17 \cdot 10^{3}$ & $2.02 \cdot 10^{3}$ \\
Emulsion 5\% & $11.6 \cdot 10^{3}$ & $6.54 \cdot 10^{3}$ & $3.36 \cdot 10^{3}$ \\
Emulsion 10\% & $22.4 \cdot 10^{3}$ & $11.4 \cdot 10^{3}$ & $4.23 \cdot 10^{3}$ \\
\hline
\end{tabular}

velocity of such liquid $v_{\mathrm{c} 0}$ can be calculated using the wellknown Hagen-Poiseuille relationship

$v_{\mathrm{c} 0}=\frac{\Delta p Y^{2}}{A \eta L}$,

where $\Delta p$-pressure difference at the ends of the capillary, $Y$-distance from the axis to the capillary wall, $\eta$ - viscosity of the continuous phase, $L$-capillary length, and $A-$ constant equal to 2 for a cylindrical capillary (Kembłowski et al. 1985).

Knowing that in such a case $v_{\mathrm{c} 0}=Q_{\mathrm{v}} / S$, where $S$ is the crosssectional area of the channel, then $\Delta p$ can be determined on the basis of formula (2). The velocity distribution in a symmetrical capillary can therefore be calculated from the formula

$v_{\mathrm{c} 0}=\frac{\Delta p}{A \eta L}\left(Y^{2}-y^{2}\right)$,
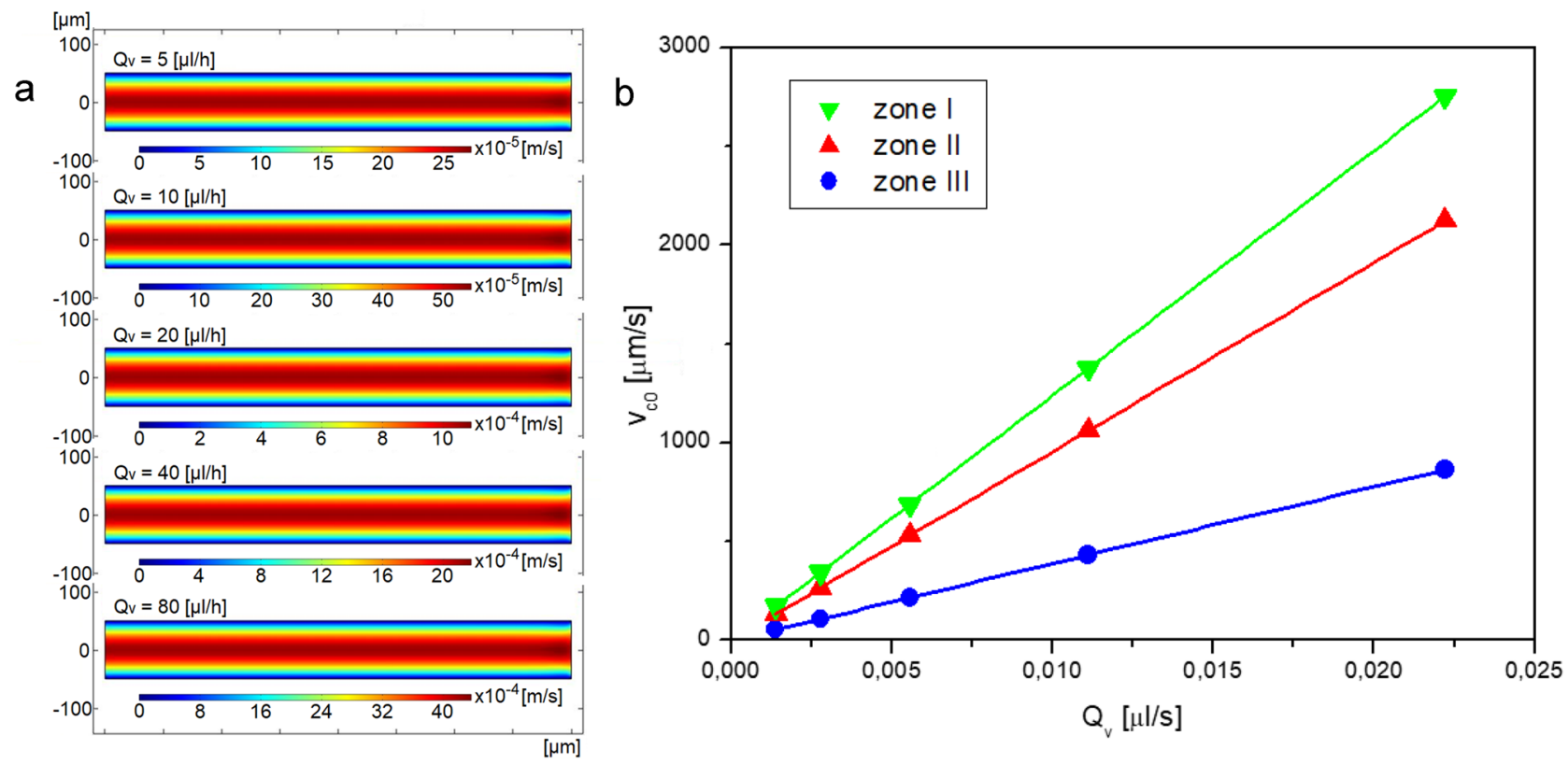

Fig. 11 Predictions of continuous phase flow velocity: a simulations of continuous phase flow in a capillary at different flow rates and $\mathbf{b}$ dependence of the velocity of the continuous phase on the flow rate for three zones 
where $y$-distance from the capillary axis to the place where the drop is, and $Y$-distance from the axis to the capillary wall.

Assuming the value of $y$, respectively, the average distances from the center of the capillary $x_{\mathrm{I}}, x_{\mathrm{II}}$, and $x_{\mathrm{III}}$ equal to $8.33 \mu \mathrm{m}, 25 \mu \mathrm{m}$, and $41.67 \mu \mathrm{m}$, the velocity of the continuous phase can be calculated when there are no oil drops in the capillary, i.e., $\varphi_{f}=0$. This allowed to calculate the velocity value $\mathrm{v}_{\mathrm{c} 0}$ for the three zones considered at different values of the liquid flow rate. The results of these calculations are presented in Fig. $11 \mathrm{~b}$.

The dependence of the velocity of the continuous phase, calculated on the condition $\varphi_{f}=0$, in relation to the liquid flow rate, was described by means of a straight line (1), and the directional coefficients a for zone I, II, and III were, respectively, $a_{\mathrm{OI}}=12.39 \cdot 10^{4} ; a_{\mathrm{OII}}=9.55 \cdot 10^{4} ; a_{\mathrm{OII}}=3.89 \cdot 10^{4}$. Then, the values of parameters $a_{\mathrm{k}}$ were divided by the values of parameters $a_{0}$ corresponding to the zone and the percentage was calculated. The results of these calculations are presented in Fig. 12 in relation to the distance from the capillary axis.

On the basis of the graph in Fig. 12, it can be read what is the percentage ratio of the directional factors for the description of the droplet displacement velocity and the flow velocity of the continuous phase at $\varphi_{f}=0$ in relation to the distance from the capillary axis for different concentrations of the emulsion. This gives some information on what percentage is the droplet velocity in relation to the continuous phase velocity when there is no dispersed phase in the system. As can be read, for the first zone, this share is the highest and increases for higher emulsion concentrations. For the $10 \%$ emulsion, as much as $17 \%$ share can be noted, which suggests that the dispersed phase velocity in this zone will constitute $17 \%$ of the continuous phase velocity when it flows independently through the capillary at a given flow rate. In the case of $2.5 \%$ emulsions, this share is over $8 \%$. In zone III, a clear effect of concentration on the $a_{\mathrm{k}} / a_{0}$ ratio can be seen. However, in zone III, there are already some fluctuations. Similar values were obtained here for emulsions with concentrations of $10 \%$ and $5 \%$. However, capturing the results of experimental studies of droplet transport through the capillary in the presented manner gives information on the basis of which it is possible to estimate the droplet velocity depending on the capillary axis for the given flow conditions. Assuming a specific flow rate, the velocity of the continuous phase (when $\varphi_{f}=0$ ) can be calculated from the dependencies (2) and (3). Then, knowing the constant $a_{0}$, it is possible to estimate the value of $a_{\mathrm{k}}$ based on the data in Fig. 10. With the $a_{\mathrm{k}}$ value, using the simple relationship (1), it is possible to determine the drop velocity $v_{\mathrm{k}}$ for a given flow rate. Of course, the results presented in this paper concern only three concentrations of emulsions; however, expanding the experience in this area and supplementing the diagram in Fig. 12 with other data, it may become a valuable tool in determining the speed of oil droplets in capillaries. This could become a significant contribution to the design of a variety of polydisperse drug carriers.
Fig. 12 The dependence of the ratio of the directional coefficients on the distance from the capillary axis

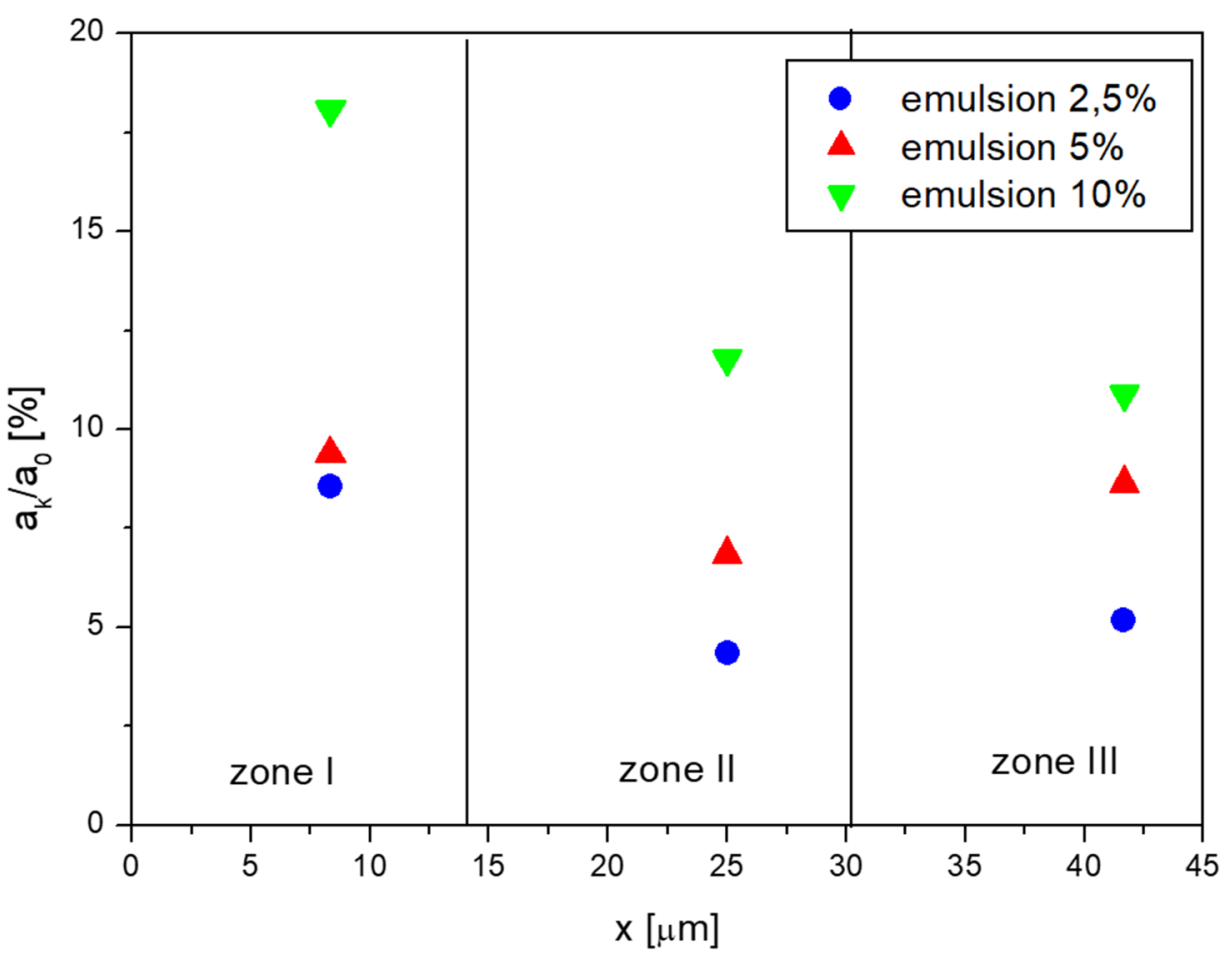




\section{Conclusions}

Based on the experimental work carried out, it was possible to draw detailed, quantitative conclusions concerning the mechanism of transport of oil drops in the capillary. It has been noted that the droplets with the largest diameters flow faster than those of relatively smaller sizes, if they are at a similar distance from the channel axis. It can be explained by the fact that when the droplets are small, the water bypasses them, while when their diameter is larger, the continuous phase acts on them as a piston and carries them away, giving them more speed. Moreover, the droplet flow velocity through the capillary is not constant but fluctuates temporarily. These fluctuations are greater for large droplets than for smaller droplet sizes. This means that large droplets are more likely to fluctuate in flow, while smaller droplets travel their way at a relatively uniform speed. The path of one drop is dependent on the presence of other droplets as they interact continuously. The changing trajectory of the droplets causes significant changes in their linear velocities. Larger diameter droplets tend to flow closer to the center of the capillary, while smaller droplets are pushed to the sides. The speed of the oil droplets in the capillaries is influenced by both their diameter and their location in relation to the capillary axis. At slow flows, with small values of the set flow rate, the main movement of the emulsion droplets takes place in the center of the channel, while on the sides, this flow is relatively slow or close to zero. The concentration of the emulsion is also important. Based on the research, it was noticed that the droplet flow velocity was higher at higher emulsion concentrations. The occurrence here, on one hand, of an increase in the viscosity of the system caused by an increase in the concentration, and on the other hand, an increase in the pressure of the continuous phase on the drops allows to expect a certain optimum concentration of the emulsion at which the speed of the droplets' movement will be the highest. In addition, the increase in the concentration of the emulsion affects the speed of the droplets moving along the capillary walls. This is due to the fact that at high concentrations of the emulsion, the continuous phase has a problem with circumnavigation of the droplets and seeks space for this. Due to the high concentration of droplets, this space is limited, so the continuous phase acts as a piston instead of flowing around the droplets.

The modeling works allowed to find that the velocity of droplets of oil in emulsions is in the range up to $20 \%$ of the velocity of emulsion treated as the continuous, single-phase medium. On the basis of the proposed dependencies, the experimental data of the transport of polydisperse emulsions in the capillary give the possibility to estimate the droplet velocity of the dispersion phase depending on the capillary axis for the given flow conditions. It is extremely important when there is a need to determine after what time drops of a certain size are able to reach a designated place. Such information is valuable, inter alia, in the design of various types of drug carriers, especially when the kinetics of transport of emulsified drugs and their concentration distribution may be of the primary importance.

Supplementary Information The online version contains supplementary material available at https://doi.org/10.1007/s10404-022-02526-2.

Author contributions Conceptualization: $\mathrm{MB}$; data curation: $€ P$; formal analysis: $\mathrm{MB}, \mathrm{JS}$, and $Ł P$; funding acquisition: $\mathrm{MB}$; investigation: $\mathrm{MB}$ and $€ P$; methodology: $\mathrm{MB}$; project administration: $\mathrm{MB}$; resources: $\mathrm{MB}$, JS, and $€ P$; software: MB and JS; supervision: $\mathrm{MB}$; validation: $\mathrm{MB}$ and JS; visualization: $\mathrm{MB}$ and $€ P$; writing —original draft: $\mathrm{MB}$; writing—review and editing: MB.

Funding The study was financed with a research grant NCN Sonata 2019/35/D/ST8/01033.

\section{Declarations}

Conflict of interest The authors declare that they have no conflicts of interest.

Open Access This article is licensed under a Creative Commons Attribution 4.0 International License, which permits use, sharing, adaptation, distribution and reproduction in any medium or format, as long as you give appropriate credit to the original author(s) and the source, provide a link to the Creative Commons licence, and indicate if changes were made. The images or other third party material in this article are included in the article's Creative Commons licence, unless indicated otherwise in a credit line to the material. If material is not included in the article's Creative Commons licence and your intended use is not permitted by statutory regulation or exceeds the permitted use, you will need to obtain permission directly from the copyright holder. To view a copy of this licence, visit http://creativecommons.org/licenses/by/4.0/.

\section{References}

Belkadi A, Tarlet D, Montillet A, Bellettre J, Massoli P (2015) Waterin-oil emulsification in a microfluidic impinging flow at high capillary numbers. Int J Multiph Flow 72:11-23. https://doi.org/10. 1016/j.ijmultiphaseflow.2015.01.007

Belkadi A, Tarlet D, Montillet A, Bellettre J, Massoli P (2016) Study of two impinging flow microsystems arranged in series. Appl Emuls Biofuel Prod Fuel 170:185-196. https://doi.org/10.1016/j. fuel.2015.12.025

Błaszczyk M, Sęk J, Przybysz $Ł$ (2016a) Capillary bundle model for gravitational flow of emulsion through granular media and experimental validation. Chem Eng Sci 155:415-427. https://doi.org/10. 1016/j.ces.2016.08.032

Błaszczyk M, Sęk J, Przybysz Ł (2016b) Modelling and experimental study of pressure elution of high-viscosity substances with a lowviscosity liquid from granular bed. Can J Chem Eng 94(8):15481559. https://doi.org/10.1002/cjce.22524 
Błaszczyk M, Sęk J, Przybysz $Ł$ (2017) Modeling of flow resistance and concentration changes during the pressure transport of emulsion through porous media. Chem Eng Res Des 127:10-21. https://doi.org/10.1016/j.cherd.2017.08.018

Błaszczyk M, Sęk J, Przybysz $Ł ~(2020)$ Modeling and experimental data of the flow of highly concentrated emulsions in porous media. Eng Sci Tech Int J 23(6):1444-1454. https://doi.org/10.1016/j. jestch.2020.07.003

Couto A, Fernandes R, Cordeiro MNS, Reis SS, Ribeiro RT, Pessoa AM (2014) Dermic diffusion and stratum corneum: a state of the art review of mathematical models. J Controll Release 177:74-83. https://doi.org/10.1016/j.jconrel.2013.12.005

Cunha LHP, Siqueira IR, Albuquerque EL, Oliveira TF (2018) Flow of emulsion drops through a constricted microcapillary channel. Int J Multiph Flow 103:141-150. https://doi.org/10.1016/j.ijmul tiphaseflow.2018.02.015

Czajkowska-Kośnik A, Szekalska M, Winnicka K (2019) Nanostructured lipid carriers: a potential use for skin drug delivery systems. Pharm Rep 71(1):156-166. https://doi.org/10.1016/j.pharep.2018. 10.008

Di J, Gao X, Du Y, Zhang H, Gao J, Zheng A (2020) Size, shape, charge and "stealthy" surface: carrier properties affect the drug circulation time in vivo. Asian J Pharm Sci. https://doi.org/10. 1016/j.ajps.2020.07.005

Ding C, Li Z (2017) A review of drug release mechanisms from nanocarrier systems. Mater Sci Eng C 76:1440-1453. https://doi.org/ 10.1016/j.msec.2017.03.130

Dong P, Rakesh KP, Manukumar HM, Mohammed YHE, Karthik CS, Sumathi S, Mallu P, Qin H-L (2019) Innovative nano-carriers in anticancer drug delivery-a comprehensive review. Bioorganic Chem 85:325-336. https://doi.org/10.1016/j.bioorg.2019.01.019

Gordillo-Galeano A, Mora-Huertas CE (2018) Solid lipid nanoparticles and nanostructured lipid carriers: a review emphasizing on particle structure and drug release. Eur J Pharm Biopharm 133:285-308. https://doi.org/10.1016/j.ejpb.2018.10.017

Harvie DJE, Cooper-White JJ, Davidson MR (2008) Deformation of a viscoelastic droplet passing through a microfluidic contraction. $\mathrm{J}$ Non-Newtonian Fluid Mech 155:67-79. https://doi.org/10.1016/j. jnnfm.2008.05.002

Hiranphinyophat S, Otaka A, Asaumi Y, Fujii S, Iwasaki Y (2021) Particle-stabilized oil-in-water emulsions as a platform for topical lipophilic drug delivery. Coll Surf B Biointerface 197:111423. https://doi.org/10.1016/j.colsurfb.2020.111423

Huang KS, Lu K, Yeh CS, Chung SR, Lin CH, Yang CH, Dong YS (2009) Microfluidic controlling monodisperse microdroplet for 5-fluorouracil loaded genipin-gelatin microcapsules. J Controll Release 137:15-19

Ibrahim W (2018) Three dimensional rotating flow of powell-eyring nanofluid with non-Fourier's heat flux and non-Fick's mass flux theory. Res Phys 8:569-577. https://doi.org/10.1016/j.rinp.2017. 12.034

Ji Y, Bellettre J, Montillet A, Massoli P (2020) Fast oil-in-water emulsification in microchannel using head-on impinging configuration: effect of swirl motion. Int J Multiph Flow 131:103402. https://doi. org/10.1016/j.ijmultiphaseflow.2020.103402

Ji Y, Bellettre J, Montillet A, Massoli P (2021a) Effect of cross-slot configuration in microfluidics on $\mathrm{O} / \mathrm{w}$ emulsification at high throughput. MANO 25:85. https://doi.org/10.1007/s10404-021-02486-Z

Ji Y, Bellettre J, Montillet A, Massoli P (2021b) Experimental investigation on single drop breakage in two-stream impinging microchannels. Exp Fluids 62:17. https://doi.org/10.1007/ s00348-020-03124-0

Kembłowski Z, Michałowski S, Strumiłło C, Zarzycki R (1985) Theoretical fundamentals of chemical and process engineering, WNT, Warsaw
Koppula KS, Fan R, Veerapalli KR, Wan J (2016) Integrated microfluidic system with simultaneous emulsion generation and concentration. J Coll Interf Sci 466:162-167

Lee J, Babadagli T (2020) Comprehensive review on heavy-oil emulsions: colloid science and practical applications. Chem Eng Sci 228:115962. https://doi.org/10.1016/j.ces.2020.115962

Liu C, Zhang Q, Zhu C, Fu T, Ma Y, Li HZ (2018) Formation of droplet and "string of sausages" for water-ionic liquid ([BMIM] [PF6]) two-phase flow in a flow-focusing device. Chem Eng Process Proc Intensif 125:8-17

Lopes D, Puga H, Teixeira J, Lima R (2020) Blood flow simulations in patient-specific geometries of the carotid artery: a systematic review. J Biomech 111:110019. https://doi.org/10.1016/j.jbiom ech.2020.110019

Mirtaleb MS, Shahraky MK, Ekrami E, Mirtaleb A (2021) Advances in biological nano-phospholipid vesicles for transdermal delivery: a review on applications. J Drug Deliv Sci Tech 61:102331. https:// doi.org/10.1016/j.jddst.2021.102331

Nabavi SA, Vladisavljevic GT, Bandulasena MV, Arjmandi-Tash O, Manovic V (2017a) Prediction and control of drop formation modes in microfluidic generation of double emulsions by singlestep emulsification. J Coll Interf Sci 505:315-324

Nabavi SA, Vladisavljevic GT, Manovic V (2017b) Mechanisms and control of single-step microfluidic generation of multi-core double emulsion droplets. Chem Eng J 322:140-148

Nitsche LC, Kasting GB, Nitsche JM (2019) Microscopic models of drug/chemical diffusion through the skin barrier: effects of diffusional anisotropy of the intercellular lipid. J Pharm Sci 108(5):1692-1712. https://doi.org/10.1016/j.xphs.2018.11.014

Ohkawa R, Low H, Mukhamedova N, Fu Y, Lai S-J, Sasaoka M, Hara A, Yamazaki A, Kameda T, Horiuchi Y, Meikle PJ, Pernes G, Lancaster G, Ditiatkovski M, Nestel P, Vaisman B, Sviridov D, Murphy A, Remaley AT, Sviridov D, Tozuka M (2020) Cholesterol transport between red blood cells and lipoproteins contributes to cholesterol metabolism in blood. J Lipid Res 61(12):15771588. https://doi.org/10.1194/jlr.RA120000635

Patil TS, Deshpande AS (2018) Nanostructured lipid carriers-based drug delivery for treating various lung diseases: a state-of-the-art review. Int J Pharm 547(1-2):209-225. https://doi.org/10.1016/j. ijpharm.2018.05.070

Perazzo A, Tomaiuolo G, Preziosi V, Guido S (2018) Emulsions in porous media: from single droplet behavior to applications for oil recovery. Adv Coll Interf Sci 256:305-325. https://doi.org/10. 1016/j.cis.2018.03.002

Rahman H, Hossain MR, Ferdous T (2020) The recent advancement of low-dimensional nanostructured materials for drug delivery and drug sensing application: a brief review. J Mol Liq 320:114427. https://doi.org/10.1016/j.molliq.2020.114427

Ran R, Sun Q, Baby T, Wibowo D, Middelberg APJ, Zhao C-X (2017) Multiphase microfluidic synthesis of micro- and nanostructures for pharmaceutical applications. Chem Eng Sci 169:78-96

Sartipzadeh O, Naghib SM, Seyfoori A, Rahmanian M, Fateminia FS (2020) Controllable size and form of droplets in microfluidicassisted devices: effects of channel geometry and fluid velocity on droplet size. Mater Sci Eng C 109:110606

Sattari A, Hanafizadeh P, Hoorfar M (2020) Multiphase flow in microfluidics: from droplets and bubbles to the encapsulated structures. Adv Coll Interf Sci 282:102208

Scheffer K, Méheust Y, Carvalho MS, Mauricio MHP, Paciornik S (2021) Enhancement of oil recovery by emulsion injection: a pore scale analysis from X-ray micro-tomography measurements. J Pet Sci Eng 198:108134. https://doi.org/10.1016/j.petrol.2020.108134

Shah A, Aftab S, Nisar J, Ashiq MN, Iftikhar FJ (2021) Nanocarriers for targeted drug delivery. J Drug Deliv Sci Tech 62:102426. https://doi.org/10.1016/j.jddst.2021.102426 
Shin S, Hong JS, Lee KH, Lee SH (2009) Oil-free generation of small polymeric particles using a coaxial microfluidic channel. Langmuir 25:12361-12366

Shui L, Eijkel JCT, van den Berg A (2007) Multiphase flow in microfluidic systems - control and applications of droplets and interfaces. A Coll Int Sci 133:35-49

Siepmann J, Siepmann F (2012) Modeling of diffusion controlled drug delivery. J Controll Release 161(2):351-362. https://doi.org/10. 1016/j.jconrel.2011.10.006

Troendle EP, Khan A, Searson PC, Ulmschneider MB (2018) Predicting drug delivery efficiency into tumor tissues through molecular simulation of transport in complex vascular networks. J Control Release 292:221-234. https://doi.org/10.1016/j.jconrel.2018.11. 010

Xu JH, Li SW, Tostado C, Lan WJ, Luo GS (2009a) Preparation of monodispersed chitosan microspheres and in situ encapsulation of BSA in a co-axial microfluidic device. Biomed Microdevices 11:243-249

Xu QB, Hashimoto M, Dang TT, Hoare T, Kohane DS, Whitesides GM, Langer R, Anderson DG (2009b) Preparation of monodisperse biodegradable polymer microparticles using a microfluidic flowfocusing device for controlled drug delivery. Small 5:1575-1581

Xu Y, Bohns-Michalowski C, Beloqui A (2021) Advances in lipid carriers for drug delivery to the gastrointestinal tract. Cur Opin Coll Interf Sci 52:101414. https://doi.org/10.1016/j.cocis.2020.101414

Yang CH, Huang KS, Chang JY (2007) Manufacturing monodisperse chitosan microparticles containing ampicillin using a microchannel chip. Biomed Microdevices 9:253-259

Zhang M, Wang W, Xie R, Ju X, Liu Z, Jiang L, Chen Q, Chu L (2016) Controllable microfluidic strategies for fabricating microparticles using emulsions as templates. Particuology 24:18-31

Zhao C-X (2013) Multiphase flow microfluidics for the production of single or multiple emulsions for drug delivery. Adv Drug Deliv Rev 65:1420-1446

Publisher's Note Springer Nature remains neutral with regard to jurisdictional claims in published maps and institutional affiliations. 